\title{
Análise ambiental do desmatamento em área de assentamento rural no Cerrado (Mato Grosso, Brasil)
}

\section{Environmental analysis of deforestation in an agricultural settlement in the Cerrado (State of Mato Grosso, Brazil)}

\section{Análisis ambiental de la deforestación en una zona de asentamiento rural en Cerrado (Mato Grosso, Brasil)}

Gustavo Benedito Medeiros Alves

https:/ / orcid.org/0000-0003-2872-4345

gustavo.benedito@hotmail.com

Universidade Federal de Mato Gross, UFMT, Rondonópolis, MT

Simoni Maria Loverde-Oliveira

https:/ / orcid.org/0000-0002-4305-3693

si.loverde@hotmail.com

Universidade Federal de Mato Grosso, UFMT, Rondonópolis, MT

Dhonatan Diego Pessi

https:/ / orcid.org/0000-0003-0781-785X dhonatan.pessi@gmail.com

Universidade Federal de Mato Grosso do Sul, UFMS, Campo Grande, MS

Alecsandra Pazza Martarello https:/ / orcid.org/0000-0003-1855-0695 aleh.martarello@gmail.com Universidade Federal de Mato Grosso, UFMT, Rondonópolis, MT

Aparecido Vieira https:/ / orcid.org/0000-0002-8657-2856 aparecidovieira41@hotmail.com Universidade Federal de Mato Grosso, UFMT, Rondonópolis, MT

Viviane Marques Mendonça https:/ / orcid.org/0000-0002-5067-1318 viivianemm_@hotmail.com.br Universidade Federal de Mato Grosso, UFMT, Rondonópolis, MT 
Resumo: Este estudo analisou a variação espacial e temporal da cobertura vegetal de Cerrado na área do Assentamento Carimã, em Rondonópolis (MT) por meio do NDVI (Normalized Difference Vegetation Index). No intervalo de 22 anos cerca de 22,2\% da vegetação foi removida. Em 1995, antes do assentamento, a vegetação representava 34,4\%; em 2017 restavam 12,2\% da área total. Este processo induziu a grandes transformações na região e nas populações locais no que se refere aos diferentes usos e ocupação da terra. A supressão da vegetação esteve atrelada aos usos para agropecuária e turismo, com práticas de exploração que podem ter contribuindo para a perda das funções ecossistêmicas do Cerrado.

Palavras-chave: cobertura vegetal, NDVI, usos e ocupação da terra, conservação.

Abstract: The study aimed to analyze the spatial and temporal variation of the 'Cerrado' vegetation cover of the Carimã Agricultural Settlement in Rondonópolis (State of Mato Grosso) employing the NDVI (Normalized Difference Vegetation Index). In 22 years, about $18.2 \%$ of the vegetation was removed. In 1995, before the settlement, the vegetation represented $34.4 \%$; in 2017 it remained $18 \%$ of the total area. This process has led to major transformations in the region and even in local populations, especially concerning to the different land uses and occupation. The suppression of vegetation was linked to uses for agriculture and tourism, with exploration practices that may have contributed to the loss of the Cerrado ecosystem functions.

Keywords: vegetation cover, NDVI, land uses and occupation, conservation.

Resumen: Este estudio analizó la variación espacial y temporal de la cubierta vegetal de Cerrado en el área de asentamiento rural de Carimã em Rondonópolis (Mato Grosso) utilizando el NDVI (Normalized Difference Vegetation Index). En el intervalo de 22 años se eliminó aproximadamente el 18,2\% de la vegetación. En 1995, antes del asentamiento, la vegetación representaba 34,4\%; en 2017 quedaba el 18\% del área total. Este proceso condujo a cambios importantes en la región y en las poblaciones locales, con respecto a los diferentes usos y ocupación de la tierra. La supresión de la vegetación estaba vinculada a los usos para la agricultura y el turismo, con prácticas de explotación que pueden haber contribuido a la pérdida de las funciones del ecosistema del Cerrado.

Palabras clave: cubierta vegetal, NDVI, usos y ocupación de la tierra, conservación.

\section{INTRODUÇÃO}

O Cerrado lato sensu tem reconhecida magnitude em termos de biodiversidade, ampla endemia de espécies e tem acumulado constantes alterações ambientais. Sabe-se que esse hotspot tem como principal ameaça a expansão da agricultura e pecuária, que aliados ao crescimento desordenado das áreas urbanas vem gerando intensas transformações e problemas ambientais (Rumble, Angeoletto, Connop, Goddard \& Nash, 2019; Vacchiano, Santos, Angeoletto \& Silva; 2019). Neste cenário, é razoável pensar que a destruição dos habitats gera riscos preditivos para a conservação das espécies, já que surgiram e desenvolveram suas estratégias adaptativas nesta savana e agora são afetados por distúrbios além da sua capacidade de sobrevivência. Neste contexto, imensas áreas desta savana brasileira foram convertidas em pastos e monoculturas (Batistella, Valladares \& Bolfe, 2008; Machado \& Machado Filho, 2014; Reynaldo \& Loverde-Oliveira, 2015; Villela, 2016). 
Quando falamos de Cerrado estamos considerando a mais diversificada savana tropical do mundo, drenada por seis das maiores bacias hidrográficas brasileira (Brasil, 2017), e composta por um complexo de fitofisionomias, de formações e um mosaico de comunidades, cuja biodiversidade não se limita as espécies, mas também às fitofisionomias, as formações e aos ambientes de vida e, consequentemente, constituem a maior riqueza que o Brasil (Coutinho, 2006).

Segundo Merten e Minella (2002, p.33):

A expansão em larga escala das terras agrícolas moldou as paisagens brasileiras nas últimas décadas e as consequências ambientais dessas transformações ainda não estão devidamente avaliadas". No entanto, é possível afirmar que "a substituição de áreas florestadas para fins agrícolas está associada à diminuição da qualidade da água e a alteração dos processos biológicos, físicos e químicos dos sistemas naturais.

Os mananciais funcionam como receptores dos subprodutos advindos das atividades sociais tanto em áreas urbanizadas quanto naquelas destinadas a agropecuária. A vegetação que margeia as nascentes e sistemas fluviais que drenam o Cerrado brasileiro merece um destaque especial, pois funcionam como um importante componente para a manutenção da qualidade ambiental dos sistemas hídricos. Sob esta perspectiva, o presente trabalho consistiu na análise da variação espaço-temporal da cobertura vegetal no Assentamento Carimã por meio do NDVI (Normalized Difference Vegetation Index) gerando, assim, uma ferramenta indispensável para estudos de avaliação do estado de conservação e planejamento ambiental em assentamentos rurais do país. Também subsidia o entendimento da dinâmica de uso e ocupação do solo, além de incentivar a valorização dos padrões de uso sustentável do Cerrado em áreas de assentamentos rurais.

\section{ÁREA DE ESTUDO}

A pesquisa foi desenvolvida no Assentamento Carimã, com área de 5.989 hectares e aproximadamente 190 famílias assentadas. Localiza-se no município de Rondonópolis no sudeste do Estado de Mato Grosso (16³9'21"S; 5449'17"W). Encontra-se próximo ao Parque Estadual Dom Osório Stoffel e a Reserva Particular do Patrimônio Natural João Basso (Fig. 1). “A cidade de Rondonópolis, distante a $50 \mathrm{~km}$ do Assentamento Carimã é considerada o segundo polo econômico regional se solidificando cada vez mais pela implantação da agroindústria e sobretudo pela vinculação econômica ao agronegócio" (Miranda, 2005, p. 35; Reynaldo \& Loverde-Oliveira, 2015, p. 16).

O clima é o tropical úmido, com temperatura média de 24 a $26^{\circ} \mathrm{C}$, caracterizado por invernos secos (100-150 mm) e verões chuvosos (1200-1350 mm), com precipitação média anual variando de 1000-1600 mm (Alvares, Stape, Sentelhas, Gonçalvez \& Sparovek, 2014; Salton, Comunello \& Fietz, 2013). 
A vegetação regional está composta por Cerradão, Cerrados, Formação Savânica associada a vertentes e Floresta Estacional, conforme a Secretaria de Planejamento do Estado de Mato Grosso (SEPLAN, 2011).

Figura 1: Localização geográfica do Assentamento Carimã, no município de Rondonópolis,MT.
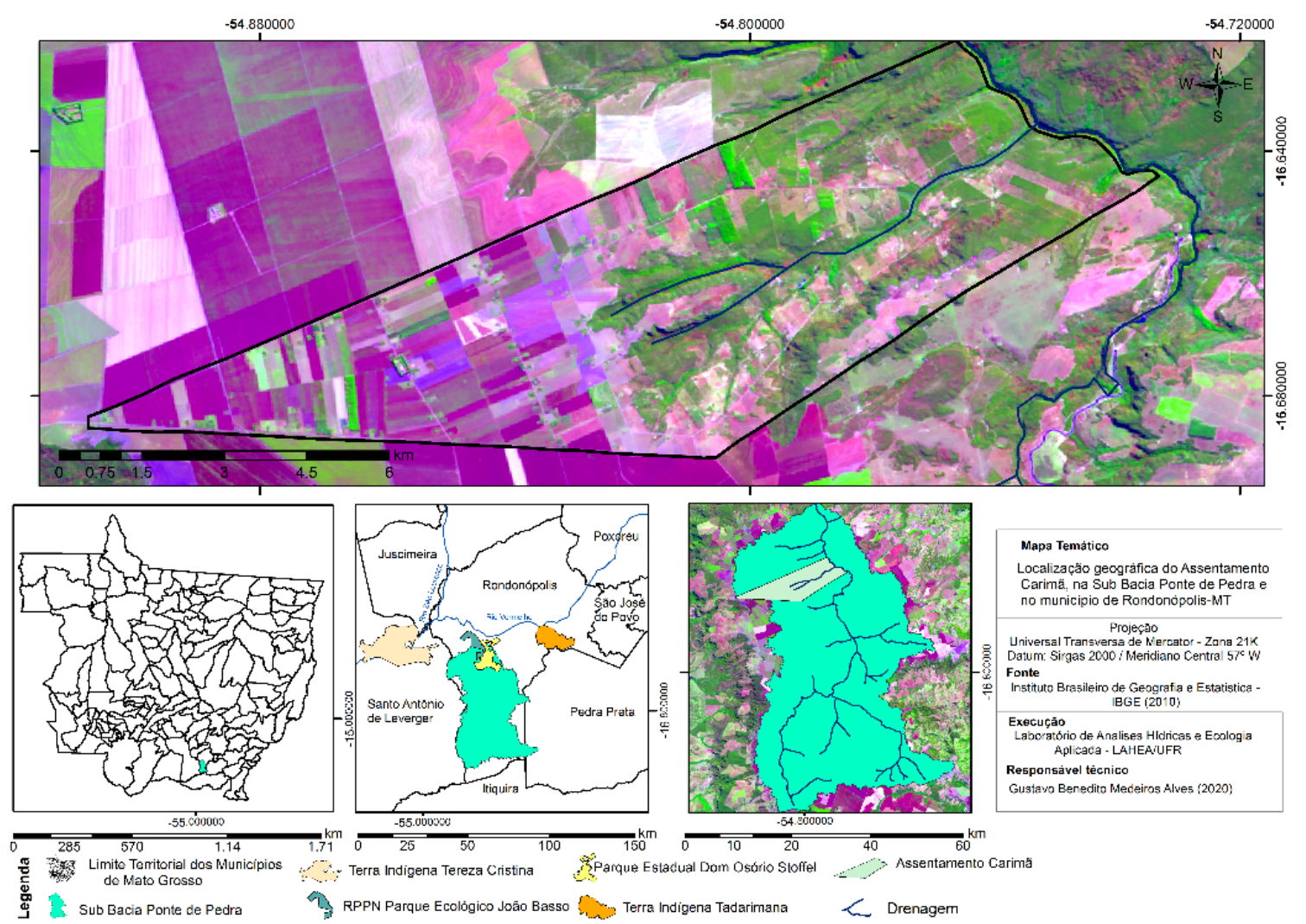

Universal Transversa de Nercator - Zana $21 \mathrm{~K}$
Datum: Sirgas 2000 ; Mendiano Central $57^{\circ} \mathrm{W}$

Fonte

Instituto Brasileiro de Gescrafa e Estatistica

Execuçãa

Laboratorio de Ana lisea Hidricas e Exolog
Aplicaca. LAHEAiUfR

Responsàvel técnico

Gustavo Benedito Medeiros Alves \{2020)

Fonte: IBGE (2010) e Imagem Landsat 8 - NASA (16/out./2014).

As principais atividades desenvolvidas no Assentamento Carimã residem na agricultura de subsistência, monoculturas (algodão, soja e milho), na pecuária extensiva destaca-se a criação de bovinos e suínos, além do perfil turístico baseado nos recursos hídricos. O curso d'água explorado é o Córrego Grande, afluente direto do rio Ponte de Pedra, pertencentes a bacia do rio Vermelho/São Lourenço, contribuintes da bacia do Pantanal (Fig. 2). No uso e ocupação da terra na bacia Ponte de Pedra predomina a classe Cultivo Temporário e Pastagem, seguidos pelos por Área Florestal, Silvicultura, Área Descoberta, Campestre e Corpo D'água Continental, conforme descrito em Pessi, Ereio, Alves, Martarello e Loverde-Oliveira (2018). 
Figura 2: Atividades realizadas no Assentamento Carimã em Rondonópolis (Mato Grosso). (A) pastagem, (B) cultivo de soja, (C) agropecuária e (D) turismo.

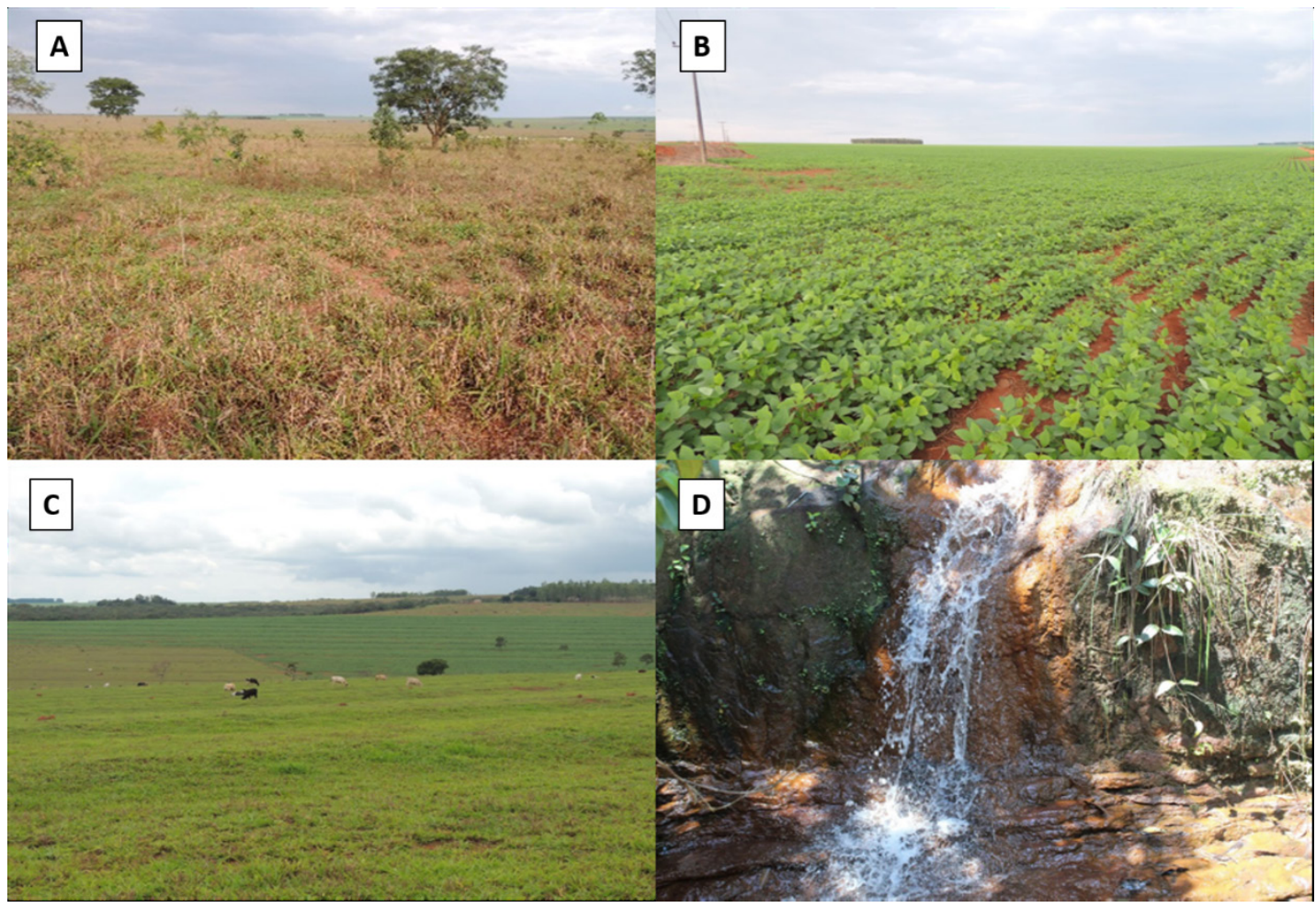

Fotos: Loverde-Oliveira, 2019.

\section{METODOLOGIA}

\section{Elevação do terreno, curvas de nível e drenagem}

O modelo digital de elevação (MDE) foi utilizado para a delimitação da elevação do terreno, das curvas de nível e para extração automática das redes de drenagens do Assentamento Carimã, de acordo com o projeto TopoData 2014.

As cartas utilizadas para a confecção do perfil das curvas de nível e redes de drenagem foram: 15S54_ZN, 15S555ZN, 16S54_ZN, 16S555ZN, 17S54_ZN e 17S555ZN no qual dados da SRTM (Shuttle Radar Topography Mission) são compatíveis com os mapeamentos na escala 1:250.000, interpoladas no Brasil de $90 \mathrm{~m}$ para $30 \mathrm{~m}$ por Krigagem (Valeriano \& Rossetti, 2008).

O processo de extração e delimitação das redes de drenagens do Assentamento Carimã foram realizadas no Sistema de Informação Geográfica (SIG) Terra View com plug in Terra Hidro 4.2.2, conforme a metodologia empregada por Alves (2015). Os dados geográficos de hipsometria e das curvas de nível foram gerados no programa ArcMap 10.2, onde foi gerado uma carta de elevação através do fatiamento da imagem com escala de 30 e de $50 \mathrm{~m}$, e as curvas com equidistância de $10 \mathrm{~m}$. Em seguida, a partir do TIN (Triangular Irregular Network), o mapa foi construído através do método de triangulação de Delaunay a partir do qual um conjunto de pontos distribuídos irregularmente no espaço gera um modelo digital de terreno (Sena, Santiago-Neto \& Leite, 2012). 
Para maior confiabilidade dos dados obtidos pelo MDE foram realizados três levantamentos de campo (11/jun./2016, 26/fev./2017 e 11/mar./2017), com auxílio de GPS (Garmin GPSMAP- 62) e máquina fotográfica (Nikon D3000 10.2 Megapixels), onde foi possível identificar as cotas altimétricas do terreno e os principais cursos hídricos que abastecem o Assentamento Carimã. Após a realização da verdade de campo, o mesmo procedimento de extração da rede de drenagem acima citado foi corrigido com as devidas localizações das nascentes e dos cursos d'água.

\section{Índice de cobertura vegetal do Assentamento Carimã}

Os índices espectrais de vegetação ou simplesmente índices de vegetação têm sido largamente utilizados para monitorar a cobertura vegetal da terra em escalas global e/ou local (Miura, Huete, Yoshioka \& Holben, 2001).

Para Portz, Guasselli e Corrêa (2012, p. 898),

O NDVI é um índice que permite monitorar, em grande escala, o "vigor" da vegetação, porque quanto mais exuberante for a vegetação menor será a porcentagem de radiação do vermelho refletida por esta. Por outro lado, quanto maior o vigor da vegetação, maior a porcentagem de radiação do infravermelho refletida.

Segundo Shimabukuro, Novo e Ponzoni (1998), esse índice é muito utilizado na estimação de biomassa verde, na estimação de cobertura vegetal e na detecção de mudanças de padrão de uso e cobertura da terra.

O estabelecimento de vegetação do Assentamento Carimã resultou das variações identificadas pelo NDVI, permitindo assim, a formulação de um Índice de Cobertura Vegetal. O índice foi determinado para cinco anos distintos (1995, 2005, 2009, 2014 e 2017), dando prioridade à imagem de satélite mais antiga e uma mais recente, na expectativa de verificar as mudanças ocorridas em termos de cobertura vegetal no período analisado. No Cerrado as datas e períodos de obtenção de imagens de satélite a serem utilizadas para analisar o NDVI é importante, pois esse bioma sofre considerável variação na fitomassa durante o ano, devido ao processo de caducifólia, especialmente quando se compara a vegetação no período chuvoso com a estiagem. Dessa forma, esta pesquisa considerou a sazonalidade utilizando imagens do mesmo período climático, baseando-se na estação seca, pois neste período as imagens de satélites encontram-se relativamente sem contaminação de nuvens.

As imagens obtidas do Instituto Nacional de Pesquisas Espaciais (INPE) foram Landsat 5 e 7, dos dias 04/ago./1995 e 08/ago./2005, e 10/jul./2009, respectivamente. Também foi empregada as imagens Landsat 8 do dia 10/jul./2014 e 16/ago./ 2017 resgatadas junto ao banco de dados da National Aeronautics and Space Administration (NASA). No software ENVI 4.7, realizou-se a correção atmosférica pelo método Dark Object Subtraction (DOS) proposto por (Chavez Jr., 1988). Uma vez corrigida, aplicou-se o cálculo do NDVI descrito por Jensen (1996, p. 45), seguindo a equação: 


$$
N D V I=(N I R-R) /(N I R+R) .
$$

Em que:

NDVI é o índice de Vegetação por Diferença Normalizada;

NIR é a refletância no comprimento de onda correspondente ao Infravermelho Próximo (Banda 4);

R é a refletância no comprimento de onda correspondente ao Vermelho (Banda 3).

Para uma melhor representação dos índices de vegetação, as imagens do NDVI foram reclassificadas, utilizando o programa ArcGis 10.2 tendo como apoio 15 pontos amostrais para a realização de verdade de campo, com auxílio do GPS e câmera fotográfica digital já citados.

\section{Entrevista com os Assentados}

As entrevistas com os moradores do Assentamento Carimã foram realizadas no período de 2014 a 2016, onde foram abordadas questões da supressão vegetal, dos cursos hídricos, da história da implantação do assentamento, dos desafios enfrentados pelos assentados, dos setores econômicos realizados (agrícola, pecuária e turismo). Foram entrevistadas 15 famílias, dentre elas algumas morando no local desde o ano da criação do assentamento, sendo desta forma testemunhas do processo de ocupação da região durante o período selecionado por esta pesquisa.

\section{RESULTADOS E DISCUSSÃO}

O NDVI e as observações de campo (in loco) permitiram afirmar que se trata de fitofisionomias de Cerrado e Cerradão, onde os valores do NDVI médio oscilaram de 0,398 a 0,608 . Destaca-se que esse comportamento espectral é congruente com outros estudos realizados no Cerrado brasileiro, com destaque para Gamarra, Teixeira-Gamarra, Carrijo, Gutiérrez e Paranhos Filho (2016), que analisaram a cobertura de vegetação (árvores e arbustos) e constaram para o NDVI valores entre 0,46 a 0,56 para o Cerrado e 0,68 a 0,82 para Cerradão. Já no estudo de Bitencourt, Mesquita Jr, Mantovani, Batalha e Pivelo (1997) foram obtidos valores de 0,38 a 0,44 para Cerrado e 0,44 até 0,55 para Cerradão.

O NDVI demonstrou que a cobertura das terras no Assentamento Carimã teve mudanças em seu padrão de proteção no tempo e espaço. Considerando que o desmatamento intenso tem provocado a degradação das terras, das nascentes e dos cursos hídricos nas áreas de interface do Cerrado com o Pantanal mato-grossense, a análise da variação espaço-temporal da cobertura vegetal por meio do NDVI demonstrou que esta atividade tem estado atrelada aos diversificados usos da terra na região.

O mapa de elevação do terreno e de curva de nível a partir da caracterização da variação altimétricas do terreno no território do Assentamento Carimã, possibilitou dividir a área em dois compartimentos distintos, permitindo realizar a quantificação absoluta e relativa da área ocupada por determinado intervalo de altitude (Fig. 3 A e B). 
Figura 3: Cota de elevação (A) e declividade do terreno (B) do Assentamento Carimã, Rondonópolis, MT.
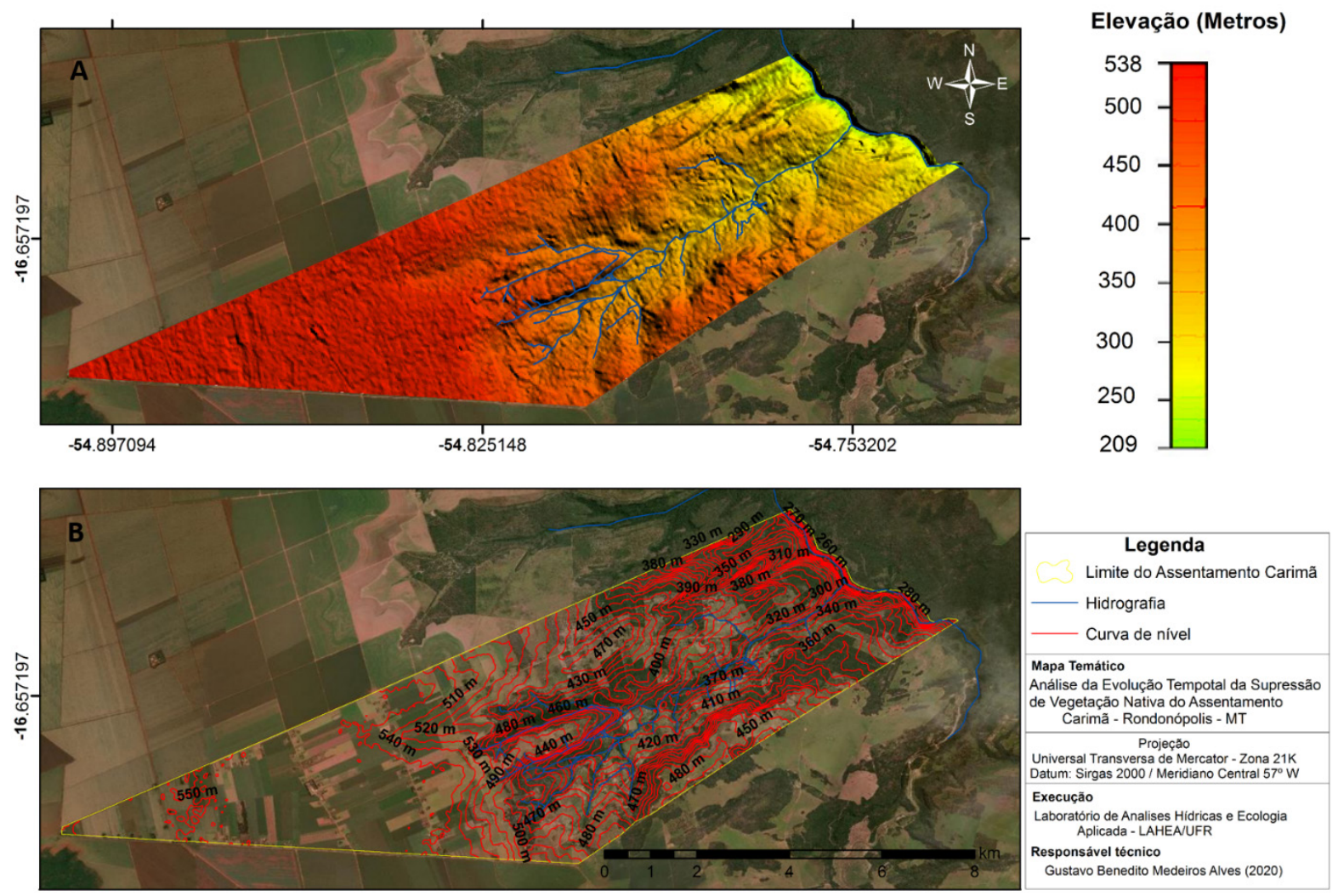

Fonte: IBGE (2010) e Imagem Landsat 8 - NASA (16/out./2014).

Observa-se que a maior parte do terreno do Assentamento Carimã encontra-se em altitudes entre 400 a 538 metros, conjugando o setor oeste, locais de chapadão. Destaca-se que é nesses intervalos de elevação que é praticada a agricultura mecanizada. Essa informação é congruente com o estudo de monitoramento das alterações da cobertura vegetal e uso do solo na Bacia do Alto Paraguai, as quais apontaram que nessas localidades estão concentradas as áreas agrícolas de Rondonópolis (WWF-Brasil, 2015). A área de planalto do Assentamento Carimã é caracterizada pela agricultura mecanizada em larga escala, com alternância entre as culturas de milho, soja e algodão (Silva, 2015). A agricultura é praticada na região desde os anos 1970, mas a produção se intensificou a partir dos anos 1980 devido aos grandes incentivos e investimentos no sistema rodoviário, em especial as BR 163 e BR 164 (Reynaldo \& Loverde-Oliveira, 2015).

Na porção central do assentamento os terrenos possuem altitudes entre 373 a 513 metros e nesses locais predomina a plantação de eucalipto, além da pecuária leiteira e de corte. Já na parte nordeste o relevo possui variação de 233 a 303 metros. São regiões com característica de fundo de vale, possuindo inúmeros corpos hídricos de menor ordem. Constata-se que nessas cotas de elevação o setor econômico que se destaca é o turismo e a pecuária leiteira e policultura pois, segundo Silva (2015), devido às barreiras naturais, principalmente, em relação ao tipo de solo e relevo.

Os mapas elaborados a partir dos resultados do NDVI mostraram claramente uma considerável diminuição da cobertura vegetal entre os anos de 1995 e 2017 (Tb. 1, Fig. 4A a E). 
Tabela 1: Área em hectares e porcentagem das classes de cobertura vegetal no Assentamento Carimã de acordo com o NDVI, 1995- 2017.

\begin{tabular}{lll}
\hline Classe & Floresta & Não Floresta \\
\cline { 2 - 3 } Período & hectares \% & hectares \% \\
\hline 1995 & $2.06034,4$ & $3.92965,6$ \\
2005 & $1.37723,0$ & $4.61277,0$ \\
2009 & $1.44324,1$ & $4.54675,9$ \\
2014 & $1.22820,5$ & $4.76179,5$ \\
2017 & 73112,2 & $5.25887,8$ \\
\hline
\end{tabular}

No intervalo de 22 anos, 22,2\% da cobertura vegetal foi suprimida da área ocupada pelo assentamento. De fato, nos últimos anos, acentuadamente a região foi dominada pela expansão agropecuária sem precedentes, advinda pelo acréscimo significativo na cultura de grãos e na pecuária. Este processo induziu grandes transformações na região e inclusive nas populações locais, principalmente no que se refere aos diferentes usos e ocupação da terra, causando conflitos entre as classes sociais.

Figura 4: Representação percentual das áreas classificadas pelo NDVI para os anos de 1995 (A), 2005 (B), 2009 (C), 2014 (D) e 2017 (E).
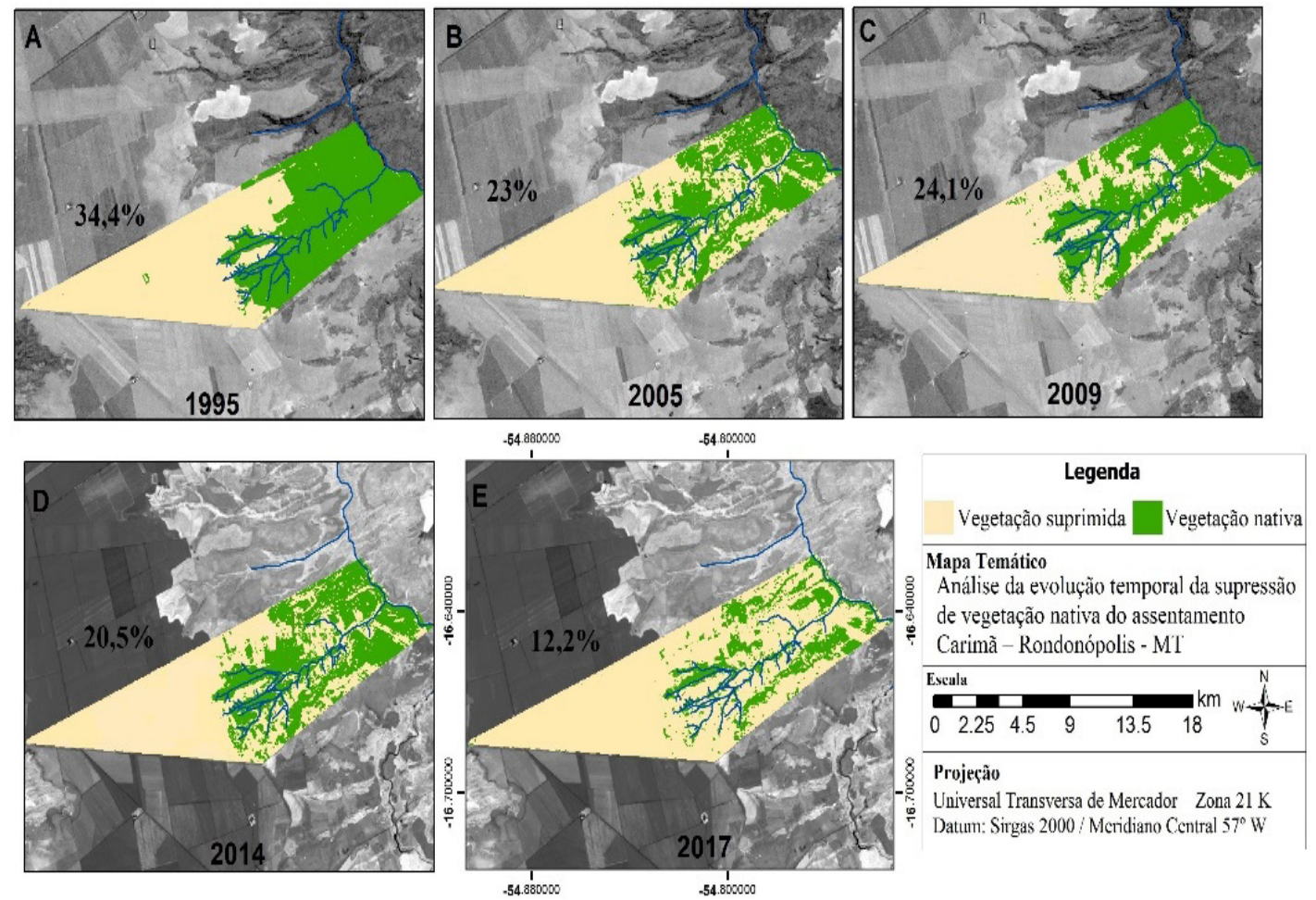

Fonte: IBGE (2010) e imagem Landsat 8 - NASA (16/out./2014).

O ponto preocupante nesta redução de cobertura vegetal é a relação direta com os processos de erosão dos solos prejudicando os sistemas fluviais e a biodiversidade (Alvarenga, Botelho \& Pereira, 2006). Segundo relato dos moradores do assentamento " $O$ córrego Grande, principal curso d'água que drena o assentamento, tem apresentado redução no volume de água nos últimos anos", e sabe-se que o uso do solo pode alterar a quantidade e a 
qualidade da água, além de influenciar o armazenamento de água subterrânea e o regime de nascente e dos cursos d'água (Pinto, Botelho, David \& Ferreira, 2004).

O desmatamento da área do Assentamento Carimã teve início com a divisão do assentamento em lotes através do INCRA. Parte das 190 famílias foi contemplada com terras denominadas de chapadão e o restante foi inserido em áreas de Cerrado ainda preservado. Estas, com lotes nas áreas onde há maiores declives do terreno acabaram abrindo ao longo do tempo o espaço necessário para a pecuária leiteira, o turismo e a policultura. Conforme já foi evidenciado na literatura (Garcia, 2016; S. R. S. A. Ávila, M. Ávila, Bernardi \& Couto Júnior, 2019) os assentamentos conduzem suas atividades com produções adaptadas em pequena escala, acompanhadas de uma dinâmica de desmatamento ocasionada pela ocupação predominante da pecuária leiteira, policultura seguido de culturas anuais (soja e milho).

Nota-se que as florestas remanescentes, cujos índices de cobertura vegetal são altos, estão concentradas na porção nordeste, leste e sudeste do assentamento, região identificada com presença de depressão e fundos de vales (Fig. 3B). As condições do relevo do local contribuíram de certa forma para preservar a floresta que está situada próxima aos cursos hídricos. No ano de 1995, que antecede a implantação do Assentamento Carimã em 1997, a cobertura da vegetação representava 34,4 \% dos 5.989 hectares. Já em 2005 ocorreu um aumento significativo na área desmatada, chegando a $23 \%$ da vegetação. Os moradores relataram que foi próximo a esse período que iniciou a introdução da agricultura de larga escala (monoculturas), além do cultivo do eucalipto (Fig. 4A e B).

Neste sentido, Gosch (2015, p.104) ao analisar a dinâmica de desmatamento em áreas de assentamentos no Cerrado revelou que:

As regiões com uso mais intensivo do solo (seja com agricultura ou pecuária) tendem a um maior percentual de desmatamento, tanto regionalmente como dentro dos assentamentos. Com isso, pode-se afirmar que os assentamentos são "frutos do meio" onde estão inseridos, e acompanham a dinâmica regional de desmatamento ou de conservação, tendendo às mesmas atividades econômicas de seu entorno. Conclui-se, portanto, que os assentamentos rurais da reforma agrária no bioma Cerrado não são terras isoladas da realidade local, da mesma forma que seus pequenos agricultores assentados não podem ser caracterizados como os atores principais das mudanças do uso do solo.

Dentre os entrevistados, 80\% disseram que na ocasião do assentamento em 1997 seus lotes já apresentavam alterações e haviam sido explorados com a retirada da madeira e vegetação nativa, visto não terem sido os primeiros donos dos lotes. Os moradores que residem no local desde a criação do assentamento relataram que o desmatamento foi realizado para limpar suas propriedades e poder cultivar e criar animais.

De acordo com Novaes, Lobo e Ferreira (2008, p.128):

Com a expansão da fronteira agrícola a partir da década de70, o Cerrado ganha uma nova configuração territorial, com atividades mecanizadas para o campo, proporcionando 
concentração de terra, desta forma desencadeando inúmeras degradações ambientais neste bioma, até mesmo gerando grandes prejuízos econômicos e sociais.

Em 2009, a área de vegetação do assentamento aumentou 1,1\% em comparação ao ano de 2005 (Fig. 4B e C). Uma das possíveis explicações, conforme declarado pelos entrevistados, foram os reflorestamentos com eucalipto usados como uma prática agroflorestal pelos pecuaristas nas áreas com maiores declives dentro do assentamento.

No ano de 2014, a supressão vegetal do assentamento chegou a 20,5\%, já no ano de 2017 a vegetação foi reduzida para 12,2\%, sendo que as áreas mais afetadas foram aquelas próximas aos cursos hídricos, locais esses utilizados para a realização do turismo na região (Fig. 4D e E).

Os rios localizados no Assentamento Carimã, além de cumprirem sua função ecossistema, são explorados pelo ecoturismo. Apesar disto, Pessi, Ereio, Alves, Martarello e Loverde-Oliveira (2018) observaram que nesta região o desmatamento visando a expansão da agropecuária é o que mais avança sobre as Áreas de Preservação Permanente das nascentes e rios.

Baccaro (200, p. 142) ressalta que:

Os maiores problemas da degradação ambiental em específico ao desmatamento em áreas próximas e dentro de assentamentos estão: o uso inadequado e irracional da terra, possuindo a tendência de fragmentar áreas de vegetação natural, assoreamento dos cursos d'água, e o desencadeamento de processos erosivos, afetando até mesmo o próprio ciclo hidrológico em questão.

Diante deste panorama, finalizamos afirmando que houve uma intensa transformação na vegetação nativa do Assentamento Carimã, fator este atrelado ao crescimento econômico regional com a consolidação da pecuária, do turismo e da produção agrícola. Este crescimento foi acompanhado por um prejuízo ambiental, com grande retração da vegetação natural e consequente perda da biodiversidade associada.

\section{CONSIDERAÇÕES FINAIS}

O uso de ferramentas para o processamento de imagens de satélite, especificamente o NDVI, mostrou-se bastante eficiente e preciso para a identificação da cobertura vegetal de Cerrado. Dessa maneira, foi possível elaborar informações geográficas que podem auxiliar na gestão ambiental desse território, onde os níveis, ou índices de cobertura vegetal vem passando por supressão.

Em relação ao entendimento dos moradores sobre o processo que levou ao aumento do índice de desmatamento, bem como os impactos ambientais, a consciência de que é preciso ações de mitigação foi quase consensual. Foi possível também relacionar as experiências vividas em relação ao desmatamento e a noção de valor do ambiente atribuída pelos assentados. 


\section{REFERÊNCIAS}

Alvarenga, Andréia P., Botelho, Soraya, A., \& Pereira, Israel M. (2006). Avaliação da regeneração natural na recomposição de matas ciliares em nascentes na região sul de Minas Gerais. Cerne, 12(1):360-372.

Alvares, Clayton A., Stape, José L., Sentelhas, Paulo C., Gonçalvez, José L.M., \& Sparovek, Gerd. (2014). Koppen's climate classification map for Brazil. Meteorologische Zeitschrift, 22(1):711-728.

Alves, Gustavo B.M. (2015). Efeito da inundação sobre o manejo da pecuária no pantanal Norte com emprego de imagens orbitais. (Dissertação de Mestrado em Geografia). Universidade Federal do Mato Grosso, UFMT, Rondonópolis, MT, Brasil. Recuperado de https://www.ufmt.br/ppgeo_cur/arquivos/ ad524d988cbb61443f8cb92252fa9f5b.pdf

Ávila, Silvia R.S.A., Ávila, Mario, Bernardi, José V. E., \& Couto Júnior, Antônio F. (2019). Estudo exploratório sobre dinâmica do desmatamento em assentamentos localizados no território portal da Amazônia. Revista Retratos de Assentamentos, 22(1):139-152. https://doi.org/10.25059/2527-2594/ retratosdeassentamentos/2019.v22i1.330

Baccaro, Claudete A.D. (2007). Processos erosivos no domínio do Cerrado. In: Guerra, A. J. T. Guerra, A.S. Silva, \& R.G.M. Botelho (Org.) Erosões e Conservação dos Solos: Conceitos, Temas e Aplicações. (3a ed.). Rio de Janeiro: Bertrand Brasil.

Batistella, Matheus, Valladares, Gustavo S., \& Bolfe, Edson L. (2008). Monitoramento da expansão agropecuária como Subsídio à gestão ambiental estratégica na Região Oeste da Bahia, Brasil. In M. Batistella, \& E.F. Moran. Geoinformação e monitoramento ambiental na América Latina. (pp.163-195). São Paulo: SENAC.

Bitencourt, Marisa D., Mesquita Jr, Humberto N., Mantovani, Waldir., Batalha, Marco A., \& Pivelo, Vania R. (1997). Identificação de fisionomias de Cerrado com imagem índice de vegetação. In: Laércio L. Leite, \& Carlos H. Saito (Org.) Contribuição ao conhecimento ecológico do Cerrado. (cap. 7, pp. 316-320). Brasília: Ed. UnB. Recuperado de http://ecologia.ib.usp.br/lepac/conservacao/Artigos/69_Iden_fisio.pdf

Brasil. (2017). Ministério do Meio Ambiente. Bioma Cerrado. Recuperado de http://www.mma.gov.br/ biomas/cerrado

Chavez Jr, Pat S. (1988). An improved dark object subtraction technique for atmospheric scattering correction of multispectral data. Remote Sensing of Environment, 24: 459-479.

Coutinho, Leopoldo M. (2006). O conceito de bioma. Acta Botanica Brasilica. 20(1): 1-11.

Gamarra, Roberto M., Teixeira-Gamarra, Mara C., Carrijo, Martha G. G., \& Paranhos Filho, Antonio C. (2016). Uso do NDVI na análise da estrutura da vegetação e efetividade da proteção de unidade de conservação no Cerrado. $R a^{\prime} e^{\prime} G a, 37: 307-332$.

Gosch, Marcelo S. (2015). A influência de atividades agrícolas sobre a vegetação remanescente de cerrado em assentamentos rurais no estado de Goiás. (Dissertação de Mestrado em Agronegócio). Universidade Federal de Goiás, UFG, Goiânia, GO, Brasil. Recuperado de https:// repositorio.bc.ufg.br/tede/handle/tede/4882

Instituto Brasileiro de Geografia e Estatística (2010). Limite do Brasil, Mato Grosso e seus munícipios. Recuperado de https://cidades.ibge.gov.br/brasil/mt/panorama

Jensen, John R. (1996). Introductory digital image processing: a remote sensing perspective. (2a ed.). Upper Saddle River: Prentice-Hall.

Machado, Luiz C.P., \& Machado Filho, Luiz C.P. (2014). A dialética da agroecologia: Contribuição para um mundo com alimentos sem veneno. São Paulo: Expressão Popular.

Merten, Gustavo H., \& Minella, Jean P. (2002). Qualidade da água em Bacias Hidrográficas Rurais: um desafio atual para a sobrevivência futura. Agroecologia e Desenvolvimento Rural Sustentável, Porto Alegre, 3(4):103-132.

Miranda, Jocy G. (2005). Mapeamento geotécnico e estudo da suscetibilidade à erosão na bacia do Ribeirão Ponte de Pedra (MT), escala: 1:100.000. (Tese de Doutorado em Geotecnia). Universidade de São Paulo, USP, São Carlos, SP, Brasil. Recuperado de https://teses.usp.br/teses/disponiveis/18/18132/tde-21062006162918/publico/tese.pdf 
Miura, Tomoaki, Huete, Alfredo R., Yoshioka, Hiroki, \& Holben, Brent N. (2001). An error and sensitivity analysis of atmospheric resistant vegetation indices derived from dark target-based atmospheric correction. Remote Sensing of Environment, 78:284-298.

Novaes, Pedro C., Lobo, Fabio C., \& Ferreira, Manuel E. (2008). Pobreza, desenvolvimento e conservação da biodiversidade em Goiás. In Laerte Guimarães Ferreira Jr. (Org.). A encruzilhada socioambiental: biodiversidade, economia e sustentabilidade no Cerrado. (pp.121-144). Goiânia: Ed. UFG.

Pessi, Dhonatan D., Ereio, Patrícia K.B., Alves, Gustavo B.M., Martarello, Alecssandra P., \& LoverdeOliveira, Simoni. M. (2018). Qualidade da Cobertura Vegetal em Áreas de Preservação Permanente de Nascentes. Anuário do Instituto de Geociências, 41(3):270-280.

Pinto, Lilian V.A., Botelho, Soraya A., David, Antonio C.1., \& Ferreira, Elizabeth (2004). Estudo das nascentes da bacia hidrográfica do Ribeirão Santa Cruz, Lavras, MG. Scientia Forestalis, 65:197-206.

Portz, Luana, Guasselli, Laurindo, \& Corrêa, Iran (2012). Variação Espacial e Temporal de NDVI na Lagoa do Peixe, RS (Spatial and Temporal Variation of NDVI in the Peixe Lagoon, RS). Revista Brasileira de Geografia Física, 4(5):897-908.

Reynaldo, Ney I., \& Loverde-Oliveira, Simoni (2015). Usos sociais da biodiversidade de Mato Grosso. Cuiabá: Ed. UFMT.

Rumble, Heather, Angeoletto, Fabio, Connop, Stuart, Goddard, Mark A., \& Nash, Caroline (2019). Understanding and applying ecological principles in cities. In Fabiano Lemes de Oliviera, \& Ian Mell (eds) Planning Cities with Nature (pp. 217-234). Cham: Springer.

Salton, Júlio C., Comunello, Éder, \& Fietz, Carlos R. (2013). Estimativa de índices de erosividade da chuva para o Estado de Mato Grosso. Dourados: Embrapa Agropecuária Oeste.

Sena, Felipe T.N.S., Santiago-Neto, Benavenuto V.J., \& Leite, Antonio C.S. (2012). Uso do Geoprocessamento como Subsídio à análise ambiental: Imagem SRTM na geração dos mapas hipsómetrico e de declividade das bacias difusas da barragem Boa Esperança no Estado do Piauí. Simpósio Brasileiro de Ciências Geodésicas e Tecnologias da Geoinformação. Recife, Brasil, 4. Recuperado de https:/ / www3.ufpe.br/cgtg/SIMGEOIV/CD/

Shimabukuro, Yosio E., Novo, Evelyn M., \& Ponzoni, Flávio. J. (1998). Índice de Vegetação e Modelo Linear de Mistura Espectral no Monitoramento da região do Pantanal. Pesquisa Agropecuária Brasileira, 33:17291737.

Silva, Sávio I. (2015). A produção em área de agricultura familiar e sua vinculação com o agronegócio: estudo de caso do PA Carimã em Rondonópolis/MT. (Dissertação de Mestrado em Geografia).Universidade Federal de Mato Grosso, UFMT, Rondonópolis, MT, Brasil. Recuperado de https://www.ufmt.br/ppgeo_cur/arquivos/ d66455c9faf194fdc0328a9aa92734b0.pdf

Vacchiano, Marcelo C., Santos, Jeater W., Angeoletto, Fábio, \& Silva, Normandes M. (2019). Do Data Support Claims That Brazil Leads the World in Environmental Preservation?.Environmental Conservation, 46(2):118-120.

Valeriano, Márcio M., \& Rossetti, Dilce F. (2008). TopoData: seleção de coeficientes geoestatísticos para o refinamento unificado de dados SRTM. São José dos Campos: INPE. Recuperado de http://www.dsr.inpe.br/ topodata/

Villela, Pollyana M. (2016). Impactos ambientais da modernização agropecuária em Goiás. (Dissertação de Mestrado em Ciências Ambientais). Universidade Federal de Goiás, UFG, Goiânia, GO, Brasil. Recuperado de http://repositorio.bc.ufg.br/tede/bitstream/tede/6592/5/Disserta\%C3\%A7\%C3\%A3o\%20-\%20 Pollyana\%20de\%20Mac\%C3\%AAdo\%20Villela\%20-\%202016.pdf

WWF-Brasil. (2015). Monitoramento das alterações da cobertura vegetal e uso do Solo na Bacia do Alto Paraguai Porção Brasileira. Brasília: Instituto SOS Pantanal. Recuperado de https://www. embrapa.br/documents/1354999/1529097/BAP+-+Mapeamento+da+Bacia+do+Alto+Paraguai++sum\%C3\%A1rio+executivo/a2312a90-c14f-4f39-b43d-61d6dea43556.

Data e submissão: 21/abr./2020

Data de aceite: 20/out./2020 